\title{
Multiplanar evaluation of radiological findings associated with acetabular dysplasia and investigation of its prevalence in an Asian population: a CT-based study
}

Tomohiro Mimura*, Kanji Mori, Masahiro Kitagawa, Mariko Ueki, Yuki Furuya, Taku Kawasaki and Shinji Imai

\begin{abstract}
Background: Acetabular dysplasia (AD) is a well-known cause of osteoarthritis (OA) of the hip, with its prevalence previously determined on plain radiography. The prevalence of preexisting AD was reported as $7.3 \%$ in a patientbased Asian population. Although computed tomography (CT) could evaluate AD in multiple planes, its prevalence using multiplanar CT images has not been reported. We investigated its prevalence with CT on coronal, axial, and sagittal planes and then determined if adding the axial and sagittal planes enhanced the investigation.

Methods: We retrospectively examined 52 consecutive Japanese individuals (mean age 59.4 years) who had undergone $\mathrm{CT}$ for conditions unrelated to hip disorders. The inclusion criteria of $\mathrm{CT}$ images were (1) reconstructed axial slice thickness of $\leq 1 \mathrm{~mm}$ and (2) normal pelvic rotations and tilt. Exclusion criteria were (1) age $<20$ years, (2) neither hip center could be clearly detected, (3) evidence of hip OA. The parameters used to define AD on the coronal plane were the center-edge angle, Sharp angle, acetabular index, acetabular depth ratio, and acetabulum head index. The anterior and posterior acetabular sector angles were used as axial parameters and the vertical-center-anterior margin angle as the sagittal parameter. AD prevalence was calculated using multiplanar images and then compared with the previously reported Asian prevalence using 95\% confidence intervals (CI). In this study, we defined "prevalence" as the proportion of subjects who had AD in at least one hip.

Results: The mean prevalence of AD on coronal, axial, and sagittal planes was 16.9, 15.4, and 7.7\%, respectively. The lowest prevalence found by combining the three planes was $25.0 \%$ (95\% Cl 15.2-38.2\%). This prevalence was significantly higher than that in the previously reported Asian population (7.3\%).

Conclusions: At the lowest estimate, the prevalence of AD evaluated in three planes was more than twice as high as the previously reported prevalence in Asians when we investigated its prevalence using multiplanar images. The prevalence of AD in the axial and sagittal planes was not negligible. We therefore suggest that it is important to add axial and sagittal planes' data when investigating the prevalence of AD.
\end{abstract}

Keywords: Acetabular dysplasia, Developmental dysplasia of the hip, Prevalence, Computed tomography, Multiple parameters, Multiplanar

\footnotetext{
* Correspondence: tmimura@belle.shiga-med.ac.jp

Department of Orthopedic Surgery, Shiga University of Medical Science,

Tsukinowa-cho, Seta, Otsu, Shiga 520-2192, Japan
} 


\section{Background}

Acetabular dysplasia (AD) is a well-known cause of osteoarthritis (OA) of the hip [1, 2]. The morphological abnormalities associated with $\mathrm{AD}$ result in instability of the hip joint, leading to labral tears, cartilage degeneration, and development of OA. AD is the most common cause of hip OA, especially in Asian countries [3, 4]. The parameters employed for diagnosing AD on the coronal plane are the center-edge (CE) angle [5], Sharp angle [6], acetabular index [7], acetabular depth ratio (ADR) [8], and acetabulum head index (AHI) [9]. The anterior (AASA) and posterior (PASA) acetabular sector angles [10] are used to diagnose $\mathrm{AD}$ on the axial plane, and the vertical-center-anterior margin (VCA) angle [11] is used to diagnose $\mathrm{AD}$ on the sagittal plane. Although the prevalence of $\mathrm{AD}$ has been reported using hip joint radiography, pelvic radiography, or urography, it has been discussed only in terms of the coronal plane. Umer et al. [12] reported that the prevalence of $\mathrm{AD}$ was $7.3 \%$ (CE angle $<20^{\circ}$ ) using pelvic radiography in a patientbased Asian population.

Computed tomography (CT) and magnetic resonance imaging (MRI) provide images not only of the coronal plane but also the axial and sagittal planes. No reports, however, have shown the prevalence of AD using multiplanar CT or MRI investigations. Because AD is an important etiology of OA of the hip that can reduce a patient's healthy life-span, we thought that the prevalence of $\mathrm{AD}$ should not be discussed based only on coronal plane investigations. We therefore investigated the morphological features of the acetabulum in a convenience sample of Japanese patients using reconstructed, high-resolution CT images in the coronal, axial, and sagittal planes. The aims of this study were to investigate the prevalence of $\mathrm{AD}$ on each plane and then using a combination of the three planes. Based on the results, we assessed the usefulness of adding the axial and sagittal plane for investigating the prevalence of $\mathrm{AD}$ in a Japanese population.

\section{Methods}

\section{Patients and parameters}

We conducted a study on patients who had undergone CT imaging of the chest, abdomen, and pelvis including the hip joints. The CT scans had been requested by other departments at our institution for conditions unrelated to hip disorders. The inclusion criteria were as follows: (1) the reconstructed axial slice thickness was $\leq 1 \mathrm{~mm}$ and (2) pelvic rotations and tilt were normal (described later in the section describing standardization of CT images). The exclusion criteria were as follows: (1) age under 20 years; (2) the hip center of either hip could not be clearly detected (e.g., a hip with an elliptical femoral head; and (3) evidence of hip OA in either hip (e.g., the presence of joint space narrowing, osteophytes, or subchondral bone changes, including cysts and sclerosis) [13].

We retrospectively examined 52 consecutive Japanese patients (29 men, 23 women) who met the above criteria from July 1, 2013 to July 31, 2013. Both hips were analyzed in each patient. We performed detailed analyses of the morphological parameters associated with AD obtained from high-resolution, reconstructed, multi-slice CT images (1 mm thick slices) and then calculated the prevalence of $\mathrm{AD}$. The parameters examined included the $\mathrm{CE}$ angle, Sharp angle, acetabular index, ADR, AHI, AASA, PASA, and VCA angle. The CE angle, Sharp angle, acetabular index, ADR, and AHI were measured in the coronal plane of the hip center (Figs. 1 and 2). AASA and PASA were measured on the axial plane of the hip center according to the method described by Anda et al. [10] (Fig. 3). The VCA angle was measured in a $25^{\circ}$ oblique sagittal plane of the hip center according to the method described by Needell et al. [14] (Fig. 4). AD was defined as a CE angle $<20^{\circ}$ $[15,16]$, Sharp angle $>45^{\circ}[17,18]$, acetabular index $>14^{\circ}[19,20]$, ADR $<250[15,17]$, AHI $<75 \%[15,21]$,

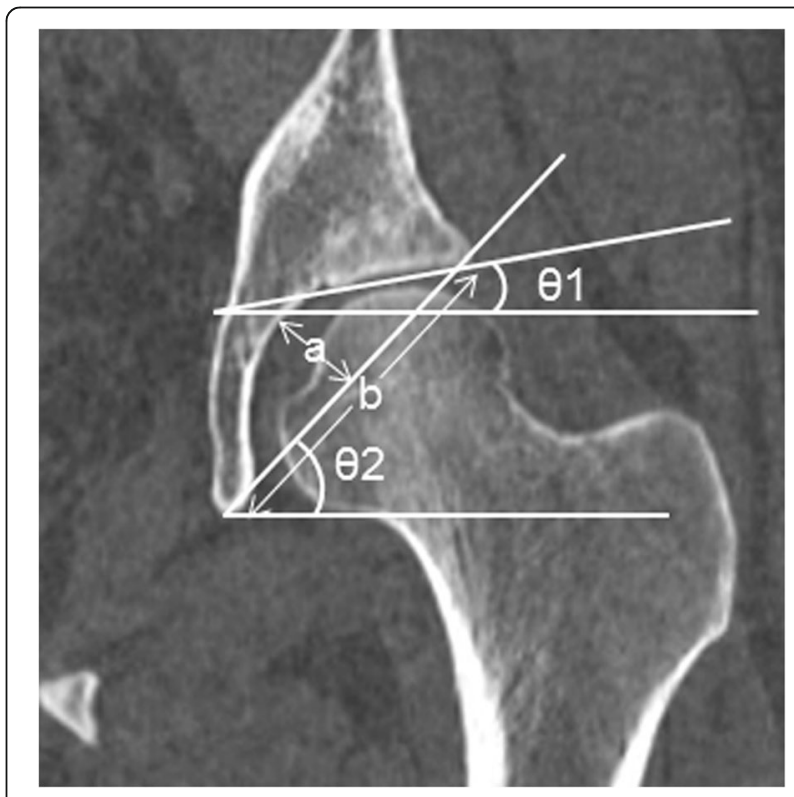

Fig. 1 Measurement of the parameters used to define acetabular dysplasia. $\theta 1$ is the acetabular index. $\theta 2$ is the Sharp angle. $a / b$ is the acetabular depth ratio (ADR). These parameters were measured on a slice of the hip center in the coronal plane, orthogonal to the standard axial plane. The acetabular index was measured as the angle between the line joining the medial and lateral aspects of the weight-bearing zone and the line parallel to the transverse axis of the pelvis. Sharp angle was measured as the angle between the line joining the lateral aspect of the weight-bearing zone and the inferior point of teardrop and the line parallel to the transverse axis of the pelvis. ADR was calculated by dividing the depth of the acetabulum by the length between the inferior teardrop point and the lateral weight-bearing zone in the coronal plane of the femoral head center, then multiplying by 1000 


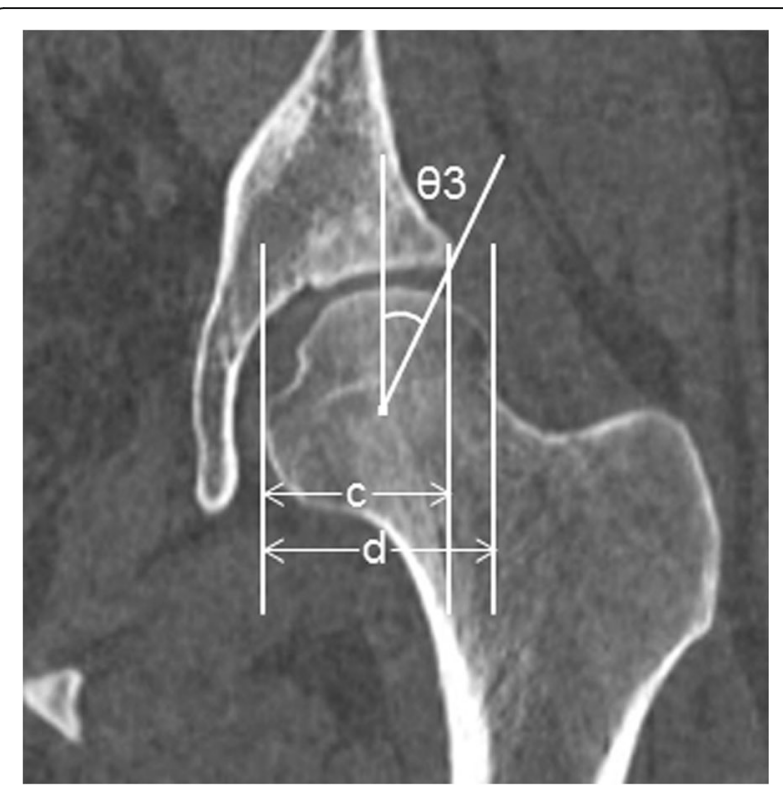

Fig. 2 Measurement of the parameters used to define acetabular dysplasia. $\theta 3$ is the center-edge (CE) angle. c/d is the acetabulum head index $(\mathrm{AHI})$. These parameters were measured on a slice of the hip center in the coronal plane. CE angle was measured as the angle between the line joining the lateral aspect of the weight-bearing zone and the femoral head center and the line perpendicular to the transverse axis of the pelvis. AHI was calculated by dividing the length from the medial margin of the femoral head to the lateral side of the weight-bearing zone by the femoral head width, then multiplying by 100

AASA $<50^{\circ}[22,23]$, PASA $<90^{\circ}[22,23]$, or VCA angle $<20^{\circ}[13,16]$. We calculated the prevalence of AD by analyzing the anatomical parameters associated with $\mathrm{AD}$ in detail using high-resolution, reconstructed, multiplanar CT images. We then compared the prevalence with that of previously reported preexisting $\mathrm{AD}$ in an Asian population (7.3\%) reported by Umer et al. [12]. The proportion of subjects who had parameters defined as $\mathrm{AD}$ in at least one hip was defined as the prevalence.

\section{Radiological examination and standardization of CT images}

All CT images were axial, sequential, and obtained in the supine position without gantry tilt $(120 \mathrm{kV}, 160 \mathrm{~mA}$, 0.5 s) using a Toshiba Aquilion CX (Toshiba Medical Systems, Tokyo, Japan). The data were reconstructed under conditions suitable for bone evaluation using AquariasNet Viewer software (TeraRecon, San Francisco, CA, USA). This software allowed reconstruction of optimal sagittal, coronal, and axial views as well as three-dimensional reconstructed CT (3D CT) views. We used the 3D CT images to confirm pelvic rotation and tilt. We confirmed (1) the rotation of the coronal plane (to investigate whether the teardrop line was horizontal), (2) the rotation of the axial plane (to examine whether the tip of the coccyx was present

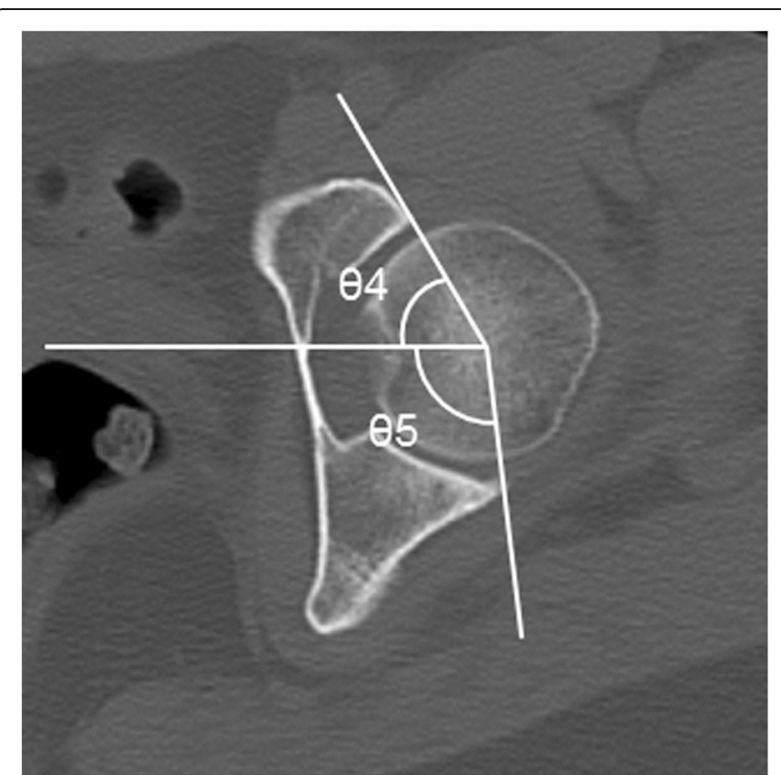

Fig. 3 Measurement of the parameters used to define acetabular dysplasia. $\theta 4$ and $\theta 5$ are the anterior acetabular sector angle (AASA) and posterior acetabular sector angle (PASA), respectively. These parameters were measured on a slice of the hip center in the axial plane. AASA was measured as the angle between the horizontal line joining the bilateral femoral head center and the line joining the anterior margin of the acetabulum and the femoral head center. PASA was measured as the angle between the horizontal line combing the bilateral femoral head center, and the line joining the posterior margin of the acetabulum and femoral head center

above the pubic symphysis) [24], and (3) the neutral pelvic tilt (to investigate the distance between the upper border of the symphysis and the mid-portion of the sacrococcygeal joint, as previously described [24]). In the present study, $32 \pm 10 \mathrm{~mm}$ in men and $47 \pm 10 \mathrm{~mm}$ in women were considered neutral.

\section{Evaluation of the interobserver and intraobserver reliability}

The interobserver reliability between the first (TM) and second (TK) observers and intraobserver reliability between the first and second assessments (TM) were evaluated for the first 20 consecutive cases.

\section{Statistical analysis}

All statistical analyses were performed using SPSS Statistics 22.0 for Windows (SPSS, Chicago, IL, USA). The 95\% confidence interval (CI) based on the score test for prevalence was estimated. Intraclass correlation coefficients (ICCs) were calculated to evaluate the interobserver and intraobserver reliability. The ICC was interpreted using the categories of agreement suggested by Landis and Koch [25], where $\leq 0.40$ is unacceptable, $0.41-0.60$ is moderate, $0.61-0.80$ is substantial, and $\geq 0.80$ is almost perfect agreement. The significance of differences between men 


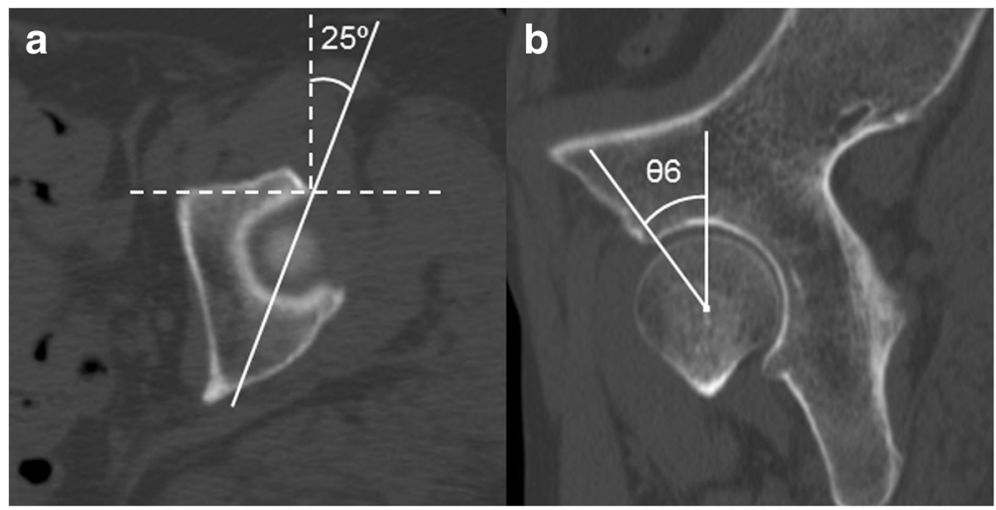

Fig. 4 Measurement of the vertical-center-anterior margin (VCA) angle on the sagittal plane. The VCA angle is measured according to the method of Needell et al. [14]. a Reference standard axial plane for measuring the VCA angle. Solid line is drawn $25^{\circ}$ obliquely from the most anterior lateral margin of the acetabulum, which is identified on the axial plane at the opening of the acetabulum. $\mathbf{b}$ Reconstructed $25^{\circ}$ oblique sagittal plane (solid line in a). $\theta 6$ is the VCA angle, which is measured between the line joining the anterior aspect of the weight-bearing zone and the hip center and the perpendicular line from the femoral head center

and women was evaluated using the Mann-Whitney $U$-test and a $X^{2}$ test. Values of $P<0.05$ were considered to indicate statistical significance.

\section{Results}

One male hip was excluded because a bone tumor was identified in the metaphyseal portion. As a result, a total of 103 hips (57 in men, 46 in female) were evaluated. Table 1 shows the mean age and all parameters for the subjects. The mean values of AASA and PASA showed significant differences between male and females. The AASA was smaller in women than in men, and PASA was smaller in men than in women.

Table 2 shows the prevalence of $\mathrm{AD}$ defined by each parameter for all subjects and by sex. The prevalence of $\mathrm{AD}$ defined by the CE angle, Sharp angle, acetabular index, ADR, AASA, and VCA angle was higher in women than in men. Among these parameters, there was a significant difference only for AASA. For the coronal parameters, the prevalence among all subjects was lowest when defined by the $\mathrm{CE}$ angle and highest with ADR. The prevalence of $\mathrm{AD}$ on the coronal plane was $11.5-23.1 \%$ for all subjects, $10.3-$ $17.2 \%$ in men, and $13.0-30.4 \%$ in women. On the axial plane, the prevalence of $\mathrm{AD}$ was $13.5-17.3 \%$ for all subjects, $6.9-23.1 \%$ in men, and $4.3-30.4 \%$ in women. The mean prevalence of $\mathrm{AD}$ defined with each parameter was $16.9 \%$ (15.1\% men, $19.1 \%$ women) on the coronal plane, $15.4 \%$ (13.8\% men, $17.4 \%$ women) on the axial plane, and $7.7 \%$ (3.4\% men, $13.0 \%$ women) on the sagittal plane.

Table 3 shows the prevalence of AD with each parameter when calculated from a combination of the planes (coronal, axial, and sagittal). In all subjects, the prevalence was lowest $(25.0 \%)$ when defined with a $\mathrm{CE}$ angle $<20^{\circ}$, AASA $<50^{\circ}$, or VCA angle $<20^{\circ}$ and highest (36.5\%) when defined by $\mathrm{ADR}<250$, PASA $<50^{\circ}$, or VCA angle $<20^{\circ}$ in all three planes. In men, the prevalence was lowest (13.8\%) when defined by $\mathrm{CE}$ angle $<20^{\circ}$, AASA $<50^{\circ}$, or VCA angle $<20^{\circ}$ and highest (34.5\%) when defined by ADR $<250$,

Table 1 Mean age and value of each parameter of all hips and by sex

\begin{tabular}{|c|c|c|c|c|}
\hline Age and parameter & All hips $(n=103)$ & Males $(n=57)$ & Females $(n=46)$ & $P$ value* \\
\hline Age (years) & $59.4 \pm 14.8(56.5-62.2)$ & $60.3 \pm 14.7(56.4-64.1)$ & $58.2 \pm 15.3(53.8-62.6)$ & 0.604 \\
\hline CE angle $\left(^{\circ}\right)$ & $31.1 \pm 7.1(29.7-32.4)$ & $31.6 \pm 7.0(29.9-33.4)$ & $30.2 \pm 7.3(28.1-32.3)$ & 0.367 \\
\hline Sharp angle $\left(^{\circ}\right)$ & $40.1 \pm 3.9(39.3-40.8)$ & $39.7 \pm 4.2(38.7-40.7)$ & $40.5 \pm 3.7(39.5-41.6)$ & 0.139 \\
\hline Acetabular index $\left(^{\circ}\right)$ & $7.0 \pm 9.8(5.1-8.9)$ & $6.0 \pm 6.5(4.4-7.6)$ & $6.8 \pm 6.6(4.8-8.7)$ & 0.346 \\
\hline ADR & $308.3 \pm 47.9(298.7-317.2)$ & $305.6 \pm 43.2(295.0-316.2)$ & $309.3 \pm 52.3(294.2-324.5)$ & 0.637 \\
\hline $\mathrm{AHI}(\%)$ & $81.9 \pm 6.0(80.7-83.2)$ & $81.6 \pm 6.1(80.1-83.1)$ & $82.4 \pm 6.3(80.5-84.2)$ & 0.673 \\
\hline $\operatorname{AASA}\left({ }^{\circ}\right)$ & $59.3 \pm 7.9(57.7-60.8)$ & $60.8 \pm 6.8(59.1-62.5)$ & $57.3 \pm 8.9(54.8-59.9)$ & 0.025 \\
\hline $\operatorname{PASA}\left({ }^{\circ}\right)$ & $98.6 \pm 9.5(96.8-100.5)$ & $96.7 \pm 10.2(94.2-99.2)$ & $100.9 \pm 8.2(98.5-103.3)$ & 0.043 \\
\hline VCA angle $\left({ }^{\circ}\right)$ & $31.1 \pm 6.0(29.9-32.2)$ & $31.2 \pm 5.5(29.8-32.5)$ & $30.9 \pm 6.7(29.0-32.9)$ & 0.831 \\
\hline
\end{tabular}

Data are shown means \pm SD with $95 \%$ confidence interval in parenthesis. $A D$ acetabular dysplasia, $C T$ computed tomography, $C E$ center edge, $A D R$ acetabular depth ratio, $A H I$ acetabulum head index, $A A S A$ anterior acetabular sector angle, PASA posterior acetabular sector angle, $V C A$ vertical-center-anterior margin angle. *Males vs females, evaluated with the Mann-Whitney $U$ test. $P$ values $<0.05$ were considered statistically significant 
Table 2 Prevalence of acetabular dysplasia cases, by each parameter in three planes

\begin{tabular}{|c|c|c|c|c|}
\hline Definition of $A D$ & All subjects $(n=52)$ & Males $(n=29)$ & Females $(n=23)$ & $P$ value* $^{*}$ \\
\hline \multicolumn{5}{|l|}{ Coronal plane } \\
\hline CE angle $<20^{\circ}$ & $\begin{array}{l}11.5 \%(6 / 52) \\
\text { (95\% Cl: } 5.4-23.0 \%)\end{array}$ & $\begin{array}{l}10.3 \%(3 / 29) \\
(95 \% \text { Cl: } 3.6-26.4 \%)\end{array}$ & $\begin{array}{l}13.0 \%(3 / 23) \\
(95 \% \mathrm{Cl}: 4.5-32.1 \%)\end{array}$ & 0.762 \\
\hline Sharp angle $>45^{\circ}$ & $\begin{array}{l}17.3 \%(9 / 52) \\
\text { (95\% Cl: } 9.4-29.7 \%)\end{array}$ & $\begin{array}{l}13.8 \%(4 / 29) \\
(95 \% \text { Cl: } 5.5-26.3 \%)\end{array}$ & $\begin{array}{l}21.7 \%(5 / 23) \\
(95 \% \text { Cl: } 9.7-41.9 \%)\end{array}$ & 0.452 \\
\hline Acetabular index $>14^{\circ}$ & $\begin{array}{l}17.3 \% \text { (9/52) } \\
\text { (95\% Cl: 9.4-29.7\%) }\end{array}$ & $\begin{array}{l}17.2 \%(5 / 29) \\
(95 \% \text { Cl: } 7.6-34.5 \%)\end{array}$ & $\begin{array}{l}17.4 \%(4 / 23) \\
(95 \% \text { Cl: } 7.0-37.1 \%)\end{array}$ & 0.989 \\
\hline$A D R<250$ & $\begin{array}{l}23.1 \%(12 / 52) \\
\text { (95\% Cl: } 13.7-36.1 \%)\end{array}$ & $\begin{array}{l}17.2 \% \text { (5/29) } \\
\text { (95\% Cl: } 7.6-34.5 \%)\end{array}$ & $\begin{array}{l}30.4 \%(7 / 23) \\
\text { (95\% Cl: } 15.6-50.9 \%)\end{array}$ & 0.262 \\
\hline $\mathrm{AHI}<75 \%$ & $\begin{array}{l}15.4 \%(8 / 52) \\
(95 \% \text { Cl: } 8.0-27.5 \%)\end{array}$ & $\begin{array}{l}17.2 \%(5 / 29) \\
(95 \% \text { Cl: } 7.6-34.5 \%)\end{array}$ & $\begin{array}{l}13.0 \%(3 / 23) \\
(95 \% \text { Cl: } 4.5-32.1 \%)\end{array}$ & 0.677 \\
\hline \multicolumn{5}{|l|}{ Axial plane } \\
\hline AASA $<50^{\circ}$ & $\begin{array}{l}17.3 \%(9 / 52) \\
(95 \% \text { Cl: } 9.4-29.7 \%)\end{array}$ & $\begin{array}{l}6.9 \%(2 / 29) \\
(95 \% \text { Cl: } 1.9-22.0 \%)\end{array}$ & $\begin{array}{l}30.4 \%(7 / 23) \\
\text { (95\% Cl: } 15.6-50.9 \%)\end{array}$ & 0.026 \\
\hline PASA $<90^{\circ}$ & $\begin{array}{l}13.5 \% \text { (7/52) } \\
\text { (95\% Cl: 6.7-25.3\%) }\end{array}$ & $\begin{array}{l}20.7 \% \text { (6/29) } \\
\text { (95\% Cl: 9.8-38.4\%) }\end{array}$ & $\begin{array}{l}4.3 \% \text { (1/23) } \\
\text { (95\% Cl: } 0.8-21.0 \%)\end{array}$ & 0.086 \\
\hline \multicolumn{5}{|l|}{ Sagittal plane } \\
\hline VCA angle $<20^{\circ}$ & $\begin{array}{l}7.7 \%(4 / 52) \\
(95 \% \text { Cl: } 3.0-18.2 \%)\end{array}$ & $\begin{array}{l}3.4 \%(1 / 29) \\
(95 \% \text { Cl: } 0.6-17.2 \%)\end{array}$ & $\begin{array}{l}13.0 \%(3 / 23) \\
(95 \% \mathrm{Cl}: 4.5-32.1 \%)\end{array}$ & 0.197 \\
\hline
\end{tabular}

$A D$ acetabular dysplasia, $C E$ center edge, $A D R$ acetabular depth ratio, $A H I$ acetabulum head index, $A A S A$ anterior acetabular sector angle, $P A S A$ posterior acetabular sector angle, VCA vertical-center-anterior margin angle. *Male vs female subjects, evaluated with a $X^{2}$ test. $P$ values $<0.05$ were considered statistically significant

PASA $<90^{\circ}$, or VCA angle $<20^{\circ}$ in all three planes. In women, the prevalence was lowest $(26.1 \%)$ when defined by a CE angle $<20^{\circ}$, PASA $<90^{\circ}$, or VCA angle $<20^{\circ}$ and highest $(47.8 \%)$ when defined by ADR $<250$, AASA $<50^{\circ}$, or VCA angle $<20^{\circ}$ in all three planes. The prevalence defined by a combination of parameters on three planes was higher in women than in men, except for a $\mathrm{CE}$ angle $<20^{\circ}$, PASA $<50^{\circ}$, or VCA angle $<20^{\circ}$. There were significant differences between men and women for three combinations: "CE angle $<20^{\circ}$, AASA $<50^{\circ}$, or VCA angle $<20^{\circ}$ "; "Sharp angle $<20^{\circ}$, AASA $<50^{\circ}$, or VCA angle $<20^{\circ}$ "; "ADR $<250$, AASA $<50^{\circ}$, or VCA angle $<20^{\circ}$."

Table 3 Prevalence of AD calculated from all combinations with each parameter in the three planes (coronal, axial, sagittal)

\begin{tabular}{|c|c|c|c|c|}
\hline Definition of AD & All subjects $(n=52)$ & Males $(n=29)$ & Females $(n=23)$ & $P$ value* \\
\hline CE angle $<20^{\circ}, \mathrm{AASA}<50^{\circ}$, or VCA angle $<20^{\circ}$ & $\begin{array}{l}25.0 \%(13 / 52) \\
\text { (95\% Cl: 15.2-38.2\%) }\end{array}$ & $\begin{array}{l}13.8 \%(4 / 29) \\
(95 \% \text { Cl: } 5.5-30.6 \%)\end{array}$ & $\begin{array}{l}39.1 \%(9 / 23) \\
(95 \% \text { Cl: } 22.2-59.2 \%)\end{array}$ & 0.036 \\
\hline CE angle $<20^{\circ}$, PASA $<90^{\circ}$, or VCA angle $<20^{\circ}$ & $\begin{array}{l}26.9 \%(14 / 52) \\
(95 \% \text { Cl: } 16.8-40.3 \%)\end{array}$ & $\begin{array}{l}27.6 \%(8 / 29) \\
(95 \% \text { Cl: } 14.7-45.7 \%)\end{array}$ & $\begin{array}{l}26.1 \%(6 / 23) \\
(95 \% \text { Cl: } 12.5-46.5 \%)\end{array}$ & 0.903 \\
\hline Sharp angle $>45^{\circ}$, AASA $<50^{\circ}$, or VCA angle $<20^{\circ}$ & $\begin{array}{l}28.8 \%(15 / 52) \\
(95 \% \text { Cl: } 18.3-42.3 \%)\end{array}$ & $\begin{array}{l}17.2 \%(5 / 29) \\
(95 \% \text { Cl: } 7.6-34.5 \%)\end{array}$ & $\begin{array}{l}43.5 \%(10 / 23) \\
(95 \% \text { Cl: } 25.6-63.2 \%)\end{array}$ & 0.038 \\
\hline Sharp angle $>45^{\circ}$, PASA $<90^{\circ}$, or VCA angle $<20^{\circ}$ & $\begin{array}{l}30.8 \%(16 / 52) \\
(95 \% \text { Cl: } 19.9-44.3 \%)\end{array}$ & $\begin{array}{l}27.6 \%(8 / 29) \\
(95 \% \text { Cl: } 14.7-45.7 \%)\end{array}$ & $\begin{array}{l}34.8 \%(8 / 23) \\
\text { (95\% Cl: 18.8-55.1\%) }\end{array}$ & 0.576 \\
\hline Acetabula index $>14^{\circ}$, AASA $<50^{\circ}$, or VCA angle $<20^{\circ}$ & $\begin{array}{l}28.8 \%(15 / 52) \\
(95 \% \text { Cl: } 18.3-42.3 \%)\end{array}$ & $\begin{array}{l}20.7 \% \text { (6/29) } \\
\text { (95\% Cl: 9.8-38.4\%) }\end{array}$ & $\begin{array}{l}39.1 \%(9 / 23) \\
(95 \% \text { Cl: } 22.2-59.2 \%)\end{array}$ & 0.144 \\
\hline Acetabula index $>14^{\circ}$, PASA $<90^{\circ}$, or VCA angle $<20^{\circ}$ & $\begin{array}{l}28.8 \%(15 / 52) \\
(95 \% \text { Cl: } 18.3-42.3 \%)\end{array}$ & $\begin{array}{l}27.6 \%(8 / 29) \\
(95 \% \text { Cl: } 14.7-45.7 \%)\end{array}$ & $\begin{array}{l}30.4 \% \text { (7/23) } \\
\text { (95\% Cl: } 15.6-50.9 \%)\end{array}$ & 0.821 \\
\hline ADR $<250$, AASA $<50^{\circ}$, or VCA angle $<20^{\circ}$ & $\begin{array}{l}32.7 \%(17 / 52) \\
(95 \% \text { Cl: } 21.5-46.2 \%)\end{array}$ & $\begin{array}{l}20.7 \% \text { (6/29) } \\
\text { (95\% Cl: 9.8-38.4\%) }\end{array}$ & $\begin{array}{l}47.8 \%(11 / 23) \\
(95 \% \text { Cl: 29.2-67.0\%) }\end{array}$ & 0.038 \\
\hline ADR $<250$, PASA $<90^{\circ}$, or VCA angle $<20^{\circ}$ & $\begin{array}{l}36.5 \%(19 / 52) \\
(95 \% \text { Cl: } 24.8-50.1 \%)\end{array}$ & $\begin{array}{l}34.5 \%(10 / 29) \\
(95 \% \text { Cl: } 19.9-52.7 \%)\end{array}$ & $\begin{array}{l}39.1 \%(9 / 23) \\
(95 \% \text { Cl: } 22.2-59.2 \%)\end{array}$ & 0.729 \\
\hline $\mathrm{AHI}<75 \%$, AASA $<50^{\circ}$, or VCA angle $<20^{\circ}$ & $\begin{array}{l}23.1 \%(15 / 52) \\
(95 \% \text { Cl: } 18.3-42.3 \%)\end{array}$ & $\begin{array}{l}20.7 \% \text { (6/29) } \\
\text { (95\% Cl: 9.8-38.4\%) }\end{array}$ & $\begin{array}{l}39.1 \%(9 / 23) \\
(95 \% \text { Cl: } 22.2-59.2 \%)\end{array}$ & 0.144 \\
\hline $\mathrm{AHI}<75 \%$, PASA $<90^{\circ}$, or VCA angle $<20^{\circ}$ & $\begin{array}{l}28.8 \% \text { (15/52) } \\
(95 \% \text { Cl: } 18.3-42.3 \%)\end{array}$ & $\begin{array}{l}27.6 \%(8 / 29) \\
(95 \% \text { Cl: } 14.7-45.7 \%)\end{array}$ & $\begin{array}{l}30.4 \%(7 / 23) \\
(95 \% \text { Cl: } 15.6-50.9 \%)\end{array}$ & 0.821 \\
\hline
\end{tabular}


The ICC values for intraobserver reliability were as follows: CE, 0.91; Sharp angle, 0.94; acetabular index, 0.88; ADR, 0.89; AHI, 0.79; AASA, 0.77; PASA, 0.85; VCA angle, 0.61 . The ICC values for the interobserver reliability also were as follows: CE, 0.83; Sharp angle, 0.94; acetabular index, 0.91; ADR, 0.93; AHI, 0.69; AASA, 0.80; PASA, 0.92; VCA angle, 0.64 .

\section{Discussion}

$\mathrm{AD}$ is one of the etiologies of hip OA, which is a major disease that affects the healthy life-span of a population [3, 26-28]. Previous reports, however, have based the prevalence of AD only on data derived from plain radiography. We conducted a detailed evaluation of the prevalence of $\mathrm{AD}$ using multiplanar $\mathrm{CT}$ images. To the best of our knowledge, this is the first study to discuss the prevalence of AD using the coronal, axial, and sagittal planes in combination. In this study, "prevalence" was defined as the proportion of subjects who had AD in at least one hip, which distinguishes it from the definition stating it is the proportion of hips "among all of the hips".

We found few studies that reported AD prevalence as just defined in an Asian population. Umer et al. [12] reported the prevalence of AD in a Singaporean population. Their report was a patient-based study with subjects similar to those in our study. They evaluated 261 asymptomatic patients (mean age 60 years, range 16-99 years), most of whom were trauma patients. They excluded patients who presented with hip pain. Pelvic radiography and a CE angle $<20^{\circ}$ was employed for their definition of AD. They reported that the prevalence of AD was $7.3 \%(19 / 261$ patients).

In the present study, we found that the prevalence, as defined with the CE angle alone, was $11.5 \%$ (95\% CI 5.4-23.0\%). According to this result, our prevalence calculated from the CE angle was similar to the $7.3 \%$ (preexisting $\mathrm{AD}$ prevalence in Asians) reported by Umer et al. [12]. However, the prevalence of AD defined with AASA $<50^{\circ}$ on the axial plane was $17.3 \%$ (95\% CI 9.4$29.7 \%$ ). This lower limit of $95 \%$ CI was higher than $7.3 \%$. The prevalence on the sagittal plane, however, was $7.7 \%$. All AD prevalence data defined using a combination of the three planes were much higher than that reported by Umer et al. (Table 3). The lowest prevalence defined using each parameter in the three planes was $25.0 \%$ (95\% CI $15.2-38.2 \%)$. Taking this lower limit of $95 \%$ CI into consideration, the prevalence of $\mathrm{AD}$ evaluated using data from three planes was at least twice as high as the previous prevalence (7.3\%) in Asians. Therefore, we believe that we should pay attention to the prevalence of AD on the axial and sagittal planes as well as the coronal plane.

Two large studies from Western countries reported the prevalence of $\mathrm{AD}$ in population based-studies using pelvic radiography $[17,18]$. Jacobsen et al. [17] studied the prevalence of $\mathrm{AD}$ in a normal Danish population. They found an $\mathrm{AD}$ prevalence of $3.4 \%$ with $\mathrm{CE} \leq 20^{\circ}$, $6.4 \%$ with Sharp angle $\geq 45^{\circ}, 3.0 \%$ with AHI $<75 \%$, and $8.8 \%$ with $\mathrm{ADR} \leq 250$ in 3859 subjects. Engesaeter et al. [18] reported the prevalence of AD in a normal Norwegian population. They surveyed 2027 young adults and found that the prevalence of $\mathrm{AD}$ was $3.3 \%$ with $\mathrm{CE}<20^{\circ}$, $13.0 \%$ with Sharp angle $>45^{\circ}, 5.8 \%$ with AHI $<75 \%$, and $12 \%$ with $\mathrm{ADR} \leq 250$. We recognized that it is difficult to compare our results with these results directly because our prevalence was calculated from a patient-based population and theirs were calculated from a normal population. It is in line, however, with our results that the prevalence of $\mathrm{AD}$ defined using the $\mathrm{CE}$ angle is low and the prevalence defined using ADR is high. We believe that defining the prevalence of AD based only the $\mathrm{CE}$ angle is not accurate and has a risk of underestimating the prevalence.

AD was generally seen more often in women $[17,26]$. In the present study, the prevalence among women was significantly higher than that of men when using only AASA as a parameter for defining AD (Table 2). There were no other significant differences in the mean values of the parameters, except AASA and PASA, between men and women (Table 1). We think that these findings with respect to axial parameters maybe be related to a retroverted acetabulum (i.e., a pincer deformity of femoroacetabular impingement). Considering these different AASA and PASA results in men and women, in our study the male acetabulum was significantly more retroverted than that in women. These results are in line with those in previous reports, which showed that a retroverted acetabulum was detected in men significantly more often than in women $[29,30]$. In other words, it is suggested that there is posterior undercoverage of the acetabulum in men and anterior undercoverage in women. We suggest that the morphological undercoverage of the acetabulum on the axial plane is a significant, clinically important finding when discussing AD. At this point, we must emphasize that these parameters cannot be evaluated using plain radiography. Additionally, we found that three combinations-CE angle $<20^{\circ} / \mathrm{AASA}<50^{\circ} / \mathrm{VCA}$ angle $<20^{\circ}$; Sharp angle $<20^{\circ} /$ AASA $<50^{\circ} / \mathrm{VCA}$ angle $<20^{\circ}$; ADR $<250 /$ AASA $<50^{\circ} / \mathrm{VCA}$ angle $<20^{\circ}$ - showed a significantly higher $\mathrm{AD}$ prevalence in women than in men (Table 3). We suggest that these findings were also affected differently by axial plane parameters in men and women.

We report herein the prevalence of $\mathrm{AD}$ based on $\mathrm{CT}$ measurements. We recognized that there was the discrepancy in the values found by $\mathrm{CT}$ and plain radiography. For example, two methods for measuring the $\mathrm{CE}$ angle on plain radiography_the classic Wiberg CE angle 
[5] and Ogata's CE angle [31]-have been reported. Chadayammuri et al. [32] reported a discrepancy in the values of the $\mathrm{CE}$ angle between plain radiography and CT. They reported that the CE angle measured with CT imaging was $2.1^{\circ}$ larger than that found using Ogata's $\mathrm{CE}$ angle on radiography. In addition, Omeroglu et al. [33] reported a discrepancy in the CE angle between Wiberg's $\mathrm{CE}$ angle and Ogata's $\mathrm{CE}$ angle determined on plain radiography. They reported that the measured values of Wiberg's CE angle were $8.9^{\circ}$ larger than those determined using Ogata's CE angle. These discrepancies were due to a difference in the measuring point on the lateral edge of the acetabulum. The measuring point of Ogata's CE angle is the lateral weight-bearing sclerotic zone (sourcil) of the acetabulum on radiography, whereas the measuring point of the classic Wiberg's CE angle is the most lateral rim of the acetabulum on radiography. Considering these facts, our results using the $\mathrm{CE}$ angle, Sharp angle, acetabular index, and AHI might slightly overestimate the prevalence of AD based on the studies that measured these parameters using Wiberg's lateral point. However, we believe that CT imaging is more suitable than plain radiography from the viewpoint of correctly measuring the parameters to evaluate AD because we can easily detect the bony morphological features of the acetabulum, especially the lateral point of the acetabular dome on CT images. We can also evaluate the correct acetabular bony coverage in the center of the hip joint. Finally, the ICC values for the interobserver reliabilities of the $\mathrm{CE}$ angle and acetabular index in the present study were 0.83 and 0.91 , respectively. Mineta et al. [34] reported that the corresponding values for CT examination were 0.94 and 0.97 , respectively. Mast et al. [35] and Tan et al. [36] reported that the ICC values for the interobserver reliability of $\mathrm{CE}$ angle evaluated in plain radiography were 0.73 and 0.51 , respectively. Mast et al. [35] and Tannast et al. [37] reported that the ICC values for the interobserver reliability of acetabular index evaluated on plain radiography ware 0.45 and 0.61 , respectively. We think that CT imaging is more suitable for measuring the morphological parameters needed to evaluate $A D$ - that $C T$ images provide a more correct prevalence of $\mathrm{AD}$ than plain radiography.

This study has some limitations. First, this study was not population-based. It was patient-based. We investigated the CT data of patients (e.g., digestive, circulatory, urological, gynecological, hematological, respiratory, kidney disease), not those of a general population. Therefore, our cohort was a convenience sample. This is an inescapable limitation of this study. We understood that it would have been better to employ healthy volunteers. It would be unethical, however, to ask volunteers to undergo CT examination only to provide data for this study. We believe that exclusion of patients of hip disorders and/or hip OA allowed us to limit this potential limitation as much as possible. In fact, our prevalence of $\mathrm{AD}$ defined as $\mathrm{CE}<20^{\circ}$ was low on the coronal plane, and our prevalence defined as ADR $<250$ was high. These results are in line with those of population-based studies of Western populations.

Second, the investigation period was short, the sample size relatively small, and the study was performed in a single hospital. Therefore, we expect that in the future similar, multicenter studies with larger sample sizes will be reported.

Third, the ICC values for intraobserver and interobserver reliability regarding the VCA angle were relatively lower than for the other parameters. We thought that the reason was the method of measurement for the VCA angle, which was clearly more complex than those for the other parameters (Fig. 4). Finally, the number of parameters employed for the definition of $\mathrm{AD}$ was different in each plane. Five parameters were employed on the coronal plane, two on the axial plane, but only one on the sagittal plane.

Stubbs et al. [38] reported that reconstructed CT images provide a better screening tool for identifying $\mathrm{AD}$ than traditional radiographic assessment. We found that evaluating $\mathrm{AD}$ in the axial and sagittal planes was useful, and the results were not negligible (Tables 2 and 3). As a result, we found that the prevalence of $\mathrm{AD}$ was higher than the preexisting $\mathrm{AD}$ prevalence based on plain radiography. We emphasize that multiplanar evaluation is useful for understanding the morphological features of $\mathrm{AD}$ and is needed to investigate the prevalence of $\mathrm{AD}$ in detail. Important measures should be taken to prevent, or at least retard, the onset of OA, thereby avoiding progression to symptomatic hip OA, which could affect patients' quality of life and be a considerable health care burden.

\section{Conclusions}

We investigated the prevalence of AD using multiplanar $\mathrm{CT}$ images in a Japanese population, which showed that the prevalence of $\mathrm{AD}$ on coronal, axial, and sagittal plane was $16.9,15.4$, and $7.7 \%$, respectively. Even at the lowest estimate, the prevalence evaluated when combing the data for all three planes was more than twice as high as the preexisting $\mathrm{AD}$ prevalence in an Asian population using only the coronal plane. We suggest that the prevalence of $\mathrm{AD}$ in the axial and sagittal planes is not negligible. Hence, it is important to add axial and sagittal plane data when investigating the prevalence of $\mathrm{AD}$.

\section{Abbreviations}

AASA: Anterior acetabular sector angle; AD: Acetabular dysplasia; ADR: Acetabular depth ratio; AHI: Acetabulum head index; CE: Center-edge; Cl: Confidence interval; CT: Computed tomography; 3D CT: Three-dimensional reconstructed $C$; ICC: Intraclass correlation coefficient; OA: Osteoarthritis; PASA: Posterior acetabular sector angle; VCA: Vertical-center-anterior margin 


\section{Acknowledgments}

The authors are grateful to T. Omori for valuable advice concerning the statistical analyses. We also thank the reviewers for their comments on the first version of this paper.

\section{Funding}

None.

\section{Availability of data and materials}

All data generated or analysed during this study are included in this published article.

\section{Authors' contributions}

TM designed and coordinated this study and wrote the manuscript. YF, MK and $\mathrm{MU}$ were involved in data collection and measurement of the parameters. TK was involved in the analysis of data. KM and SI provided suggestions and supervised the study. All authors meet the requirements for authorship including final approval of the manuscript submitted.

\section{Competing interests}

The authors declare that they have no competing interests.

\section{Consent for publication}

Not applicable.

\section{Ethics approval and consent to participate}

The ethics committee of Shiga University of Medical Science approved this study (Approval ID: 23-101). Informed consent was not obtained from the participants because we retrospectively investigated the $C T$ data on patients who previously had undergone CT imaging at our institution.

Received: 23 December 2016 Accepted: 23 January 2017 Published online: 31 January 2017

\section{References}

1. Murphy SB, Ganz R, Muller ME. The prognosis in untreated dysplasia of the hip: a study of radiographic factors that predict outcome. J Bone Joint Surg Am. 1995;77(7):985-9.

2. Albinana J, Dolan LA, Spratt KF, Morcuende J, Meyer MD, Weinstein SL. Acetabular dysplasia after treatment for developmental dysplasia of the hip: implication for secondary procedures. J Bone Joint Surg (Br). 2004;86(6):876-86.

3. Nakamura S, Ninomiya S, Nakamura T. Primary osteoarthritis of the hip joint in Japan. Clin Orthop Relat Res. 1989;241(241):190-6.

4. Takeyama A, Naito M, Shiramizu K, Kiyama T. Prevalance of femoroacetabular impingement in Asian patients with osteoarthritis of the hip. Int Orthop. 2009;33(5):1229-32.

5. Wiberg G. Studies on dysplastic acetabulum and congenital subluxation of the hip joint with special reference to the complication of osteoarthritis. Acta Chir Scand. 1939;83 Suppl 58:33.

6. Sharp IK. Acetabular dysplasia. The acetabular angle. J Bone Joint Surg (Br). 1961;43:268-72

7. Tönnis D. Congenital dysplasia and dislocation of the hip in chirdlen and adults. Berlin: Springer; 1987. p. 120.

8. Stulberg SD, Harris WH. Acetabular dysplasia and development of osteoarthritis of hip. The hip. In: Proceedings of the Second Open Scientific Meeting of the Hip Society. St. Louis: CV Mosby; 1974. p. 82-93.

9. Heyman $\mathrm{CH}$, Herndon $\mathrm{CH}$. Legg-Perthes disease. A method for the measurement of the roentogenographic results. J Bone Joint Surg Am. 1950;32:767-78

10. Anda S, Terjesen T, Kvistad KA, Sevenningsen S. Acetabular angles and femoral anteversion in dysplastic hips on adults: CT investigation. J Compt Assist Tomogr. 1991;15:115-20.

11. Lequence $M$, De Seze. False profile of the pelvis. A new radiographic incidence for the study of the hip. Its use in dysplasia and different coxopathies. Rev Rheum Mal Osteoartic. 1961;28:643-52. In French.

12. Umer M, Thambyah A, Tan WT, De Das S. Acetabular morphometry for determing hip dysplasia in the Singaporean population. J Orthop Surg (Hong Kong). 2006;14:27-31.

13. Lepage-Saucier M, Thiery C, Larbi A, Lecouvet FE, Vande Berg BC, Omoumi P. Femoroacetabular impingement: normal values of the quantitative morphometric parameters in asymptomatic hips. Eur Radiol. 2014;24:1707-14.
14. Needell SD, Borzykowski RM, Carreira DS, Kozy J. CT false-profile view of the hip: a reproducible method of measuring anterior acetabular coverage using volume CT data. Skeletal Radiol. 2014;43:1605-11.

15. Cooperman DR, Wallensten R, Stulberg SD. Acetabular dysplasia in the adult. Clin Orthop Relat Res. 1983;175:79-85.

16. Bouttier R, Morvan J, Mazieres B, et al. Reproducibility of radiographic hip measurements in adults. Joint Bone Spine. 2013;80:52-6.

17. Jacobsen S, Sonne-Holm S, Søballe K, Gebuhr P, Lund B. Hip dysplasia and osteoarthritis: a survey of 4151 subjects from the Osteoarthrosis Substudy of the Copenhagen City Heart Study. Acta Orthop. 2005;76:149-58.

18. Engesæter $\varnothing \varnothing$, Laborie LB, Lehmann TG, et al. Prevalence of radiographic findings associated with hip dysplasia in a population-based cohort of 2081 19-year-old Norwegians. Bone Joint J. 2013;95:279-85.

19. Tönnis $D$, Heinecke A. Acetabular and femoral anteversion: relationship with osteoarthritis of the hip. J Bone Joint Surg Am. 1999;81:1747-70.

20. Tannast M, Hanke MS, Zheng G, Steppacher SD, Siebenrock KA. What are the radiographic reference value for acetabular under- and overcoverage? Clin Orthop Relat Res. 2015;473:1234-46.

21. Delaunay S, Dussault RG, Kaplan PA, Alford BA. Radiographic measurements of dysplastic adults hips. Skeletal Radiol. 1997;26:75-81.

22. Akiyama M, Nakashima Y, Fujii M, et al. Femoral anteversion is correlated with acetabular version and coverage in Asian women with anterior and global deficient subgroups of hip dysplasia: a CT study. Skeletal Radiol. 2012:41:1141-8

23. Ito H, Matsuno T, Hirayama T, Tanino H, Yamanaka Y, Minami A. Threedimensional computed tomography analysis of non-osteoarthritic adult acetabular dysplasia. Skeletal Radiol. 2009;2:131-9.

24. Siebenrock KA, Kalbermatten DF, Ganz R. Effect of pelvic tilt on acetabular retroversion: a study of pelves from cadavers. Clin Orthop Relat Res. 2003:407:241-8.

25. Landis JR, Koch GG. The measurement of observer agreement for categorical data. Biometrics. 1977;33:159-74.

26. Solomon L. Patterns of osteoarthritis of the hip. J Bone Joint Surg (Br). 1976;58:176-83.

27. Harris WH. Etiology of osteoarthritis of the hip. Clin Orthop. 1986;213:21-33.

28. Lloyd-Roberts GC. Osteoarthritis of the hip. A study of the clinical pathology. J Bone Joint Surg (Br). 1953;37:8-45.

29. Mimura T, Mori K, Itakura S, Furuya Y, Kawasaki T, Imai S. Prevalence of pincer, cam, and combined deformities in Japanese hip joints evaluated with Japanese Hip Society guideline for femoroacetabular impingement: a CT-based study. J Orthop Sci. 2017;22(1):105-11.

30. Larson CM, Moreau-Gaudry A, Kelly BT, Byrd JW, Tonetti J, Lavallee S, Chabanas L, Barrier G, Bedi A. Are normal hips being labeled as pathologic? A CT-based method for defining normal acetabular coverage. Clin Orthop Relat Res. 2015;473(4):1247-54.

31. Ogata S, Moriya H, Tsuchiya K, Akita T, Kamegaya M, Someya M. Acetabular cover in congenital dislocation of the hip. J Bone Joint Surg (Br). 1990;72(2):197-201.

32. Chadayammuri V, Garabekyan T, Jesse MK, Pascual-Garrido C, Strickland C, Milligan K, Mei-Dan O. Measurement of lateral acetabular coverage: a comparison between CT and plain radiography. J Hip Preserv Surg. 2015; 2(4):392-400.

33. Omeroglu $H$, Biçimoglu $A$, Aguş $H$, Tümer Y. Measurement of center-edge angle in developmental dysplasia of the hip: a comparison of two methods in patients under 20 years old. Skeletal Radiol. 2002;31(1):25-9.

34. Mineta K, Goto T, Wada K, Tamaki Y, Hamada D, Tonogai I, Higashino K, Sairyou K. CT-based morphological assessment of the hip joint in Japanese patients: association with radiographic predictors of femoroacetabular impingement. Bone Joint J. 2016;98-B(9):1167-74.

35. Mast NH, Impellizzeri F, Keller S, Leunig M. Reliability and agreement of measure used in radiographic of the adult hip. Clin Orthop Relat Res. 2011;469(1):188-99.

36. Tan L, Aktas S, Copuroglu C, Ozcan M, Ture M. Reliability of radiological parameters measured on anteriposterior pelvis radiographs of patients with developmental of the hips. Acta Orthop Belg. 2001;67(4):347-79.

37. Tannast M, Mistry S, Steppacher SD, Reichenbach S, Langlotz F, Siebenrock KA, Zheng G. Radiographic analysis of femoroacetabular impingement with Hip2Norm-reliable and validated. J Orthop Res. 2008;26(9):1199-205.

38. Stubbs AJ, Anz AW, Frino J, Lang JE, Weaver AA, Stizel JD. Classic measures of hip dysplasia do not correlate with three-dimensional computer tomographic measures and indices. Hip Int. 2011;21:549-58. 